IRA-International Journal of Education \& Multidisciplinary Studies ISSN 2455-2526; Vol.05, Issue 02 (2016)

Pg. no. 114-118

Institute of Research Advances

http://research-advances.org/index.php/IJEMS

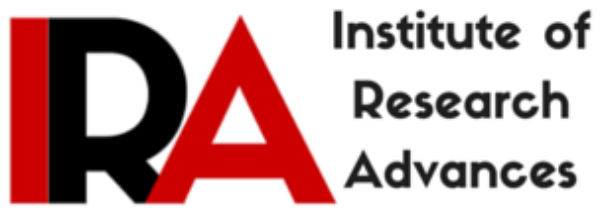

\title{
Life of Pi: A Visual Feast by Digital Cinema
}

\author{
Dr. Divya Walia \\ Assistant Professor \\ S.S Jain Subodh P G College, Jaipur, India.
}

Type of Review: Peer Reviewed.

DOI: http://dx.doi.org/10.21013/jems.v5.n2.p6

\section{How to cite this paper:}

Walia, D. (2016). Life of Pi: A Visual Feast by Digital Cinema. IRA International Journal of Education and Multidisciplinary Studies (ISSN 2455-2526), 5(2), 114-118. doi:http://dx.doi.org/10.21013/jems.v5.n2.p6

(C) Institute of Research Advances

\section{(cc) BY-No}

This work is licensed under a Creative Commons Attribution-Non Commercial 4.0 International License subject to proper citation to the publication source of the work.

Disclaimer: The scholarly papers as reviewed and published by the Institute of Research Advances (IRA) are the views and opinions of their respective authors and are not the views or opinions of the IRA. The IRA disclaims of any harm or loss caused due to the published content to any party. 


\begin{abstract}
The world of media today is undergoing substantial transformation and advancement with various media forms making the most of it to attract the audience. Digital cinematography since 2010 has been enhancing not only the visual impact of the movies but also redefining the way they are produced and created. Silver screen, the most popular form of media too keeps resorting to new innovations to increase the marketing value of its productions by exploiting the technological advancements be it in the form of graphic effects or animations to appeal the watchers. Moreover, the digital world has revolutionalized the way movies are captured thus rendering refinement to its projection on the screen. Even the distribution of the movies, these days, is done via Internet or hard drive.

In the genre of cinema, Hollywood animated movies amply exemplify the improvement that has resulted because of the contribution of the digitized world. The animated movies have now come a long way from being mere caricatures to real life characters, from being conception to concrete and surreal to real, so much so that these graphic projections are admired as well as emulated as the real life actors.

One of the masterpieces of digitised visual effects that left the world awestruck was Ang Lee's Life of $P i$, a 2012 American Adventure. It was soon perceived as a visual wonder by audiences all over the world for the use of animated technology and the realistic scenes created in $3 D$. The paper would be an attempt to examine the way visual effects have been exploited by the makers of this movie to create a successful story and a realistic depiction of imaginary on the screen.
\end{abstract}

Keywords: Animation, Hollywood, Digital Cinema, Life of Pi

The world of media today is undergoing substantial transformation and advancement with various media forms making the most of it to attract the audience. Digital cinematography since 2010 has been enhancing not only the visual impact of the movies but also redefining the way they are produced and created.In the genre of cinema, Hollywood animated movies amply exemplify the improvement that has resulted because of the contribution of the digitised world.

One of the masterpieces of digitised visual effects that left the world awestruck was Ang Lee's Life of $P i$, a 2012 American Adventure. It was soon perceived as a visual wonder by audiences all over the world for the use of animated technology and the realistic scenes created in 3D.

The story of the movie is simple and focuses on the co existence of dichotomous entities and their subsequent attempt to attain harmony for the ultimate survival. Here we see a homo sapien sharing a living space with a carnivorous beast who seems to prey upon him initially but eventually withdraws developing a kind of congeniality with its mate, realizing his significance as the sole companion and refuge in the huge ocean.

The whole movie because of its concept and story relies heavily on animations and graphics since making the beast, a tiger act or even sit in proximity with a human being, the protagonistof the film was challenging as well as dangerous. "He was 85 percent digital and 15 percent real," says visual effects supervisor (and Oscar nominee) Bill Westenhofer. "The digital character took about a year to build and featured 10 million computerized hairs. "We used complicated simulations to mimic the look and movements of the four real tigers that were used in the film. Of the 170 tiger shots in the movie, only 23 were real." (as qtd in Parade)

Besides the tiger, few other animals too are created graphically showing the success of digital cinema in deceiving eyes and mind by making them accept something unreal as real and non existent as existent. We see four non human survivors in total; A tiger, a Hyena, an orangutan and a zebra. The hungry hyena attacks rest of all except the tiger and kills them all. The whole scene is gross and 
terrifying making even readers shudder as their heart goes for the poor boy having to stay alone with a carnivorous on the boat. They all are digital creations adding to the graphic richness of the movie and winning a pat for the graphic designers. Robert Horton specifically remarks, "Life of $\mathrm{Pi}$ " is a curious experience, in large part because the movie would be impossible to shoot without extensive use of computer-generated imagery, especially involving the animals (a hyena, a zebra and an orangutan also survive the wreck).

The tiger happens to be the second most important character in the movie acting as a parallel to the main character, a boy of 16 or 17 , countering as well as complementing it. Despite being a graphic creature, it emotes well with the situation and makes one forget its digitized creation. In the scene where both the protagonist and the tiger find themselves in the midst of massive ocean, their reactions had to those of surprise and discomfort. Here simulating the tiger with all its expression was a testing effort which comes out pretty naturalistic making the audience feel like he is a real tiger in the place.



Moreover, in the absence of real tiger, it was difficult to get apt reactions from the actor, Suraj Sharma too. In one of the scenes where Pi had to ward off the tiger with a pole, director Eric de Boer had to hold the stick to bring out reactions from Sharma. The kind of visual effects that the movie creates with the tiger owe a lot to the study done by the creators on real life tigers. The real tigers had also been used but in the scenes where only tiger is in the frame, rest $85 \%$ scenes have been shot through computer generated tiger.

The movie couldn't have been what it is had there not been the contribution of digitized technology.in the words of Hortonit "wouldn't exist without digital effects and green-screen technology, because there's no way you shoot a movie in the middle of the Pacific with a real tiger. Lee and his technicians whip up a gallery of effects, including phosphorescent ocean creatures, storms at sea and, of course, the big cat, whose name is Richard Parker"

Another visual miracle of digital technology is the way ocean has been created in the movie. More than almost $70 \%$ of the movie shots are in Tsimtsum, the freighter which gets landed in Pacific Ocean after the ship wreck with two sole creatures in it. This whole ocean is created graphically in a tank with a blue screen and ocean gets simulated technologically. In an interview with Trevor Hogg, visual effects supervisors Bill Westenhofer and Guillaume Rocheron remarked, "Ang wanted the water to be as much of a character as the animals. The water and sky were essential to set the mood on the scene and that had to be visually interesting as possible to keep the audience entertained throughout." 


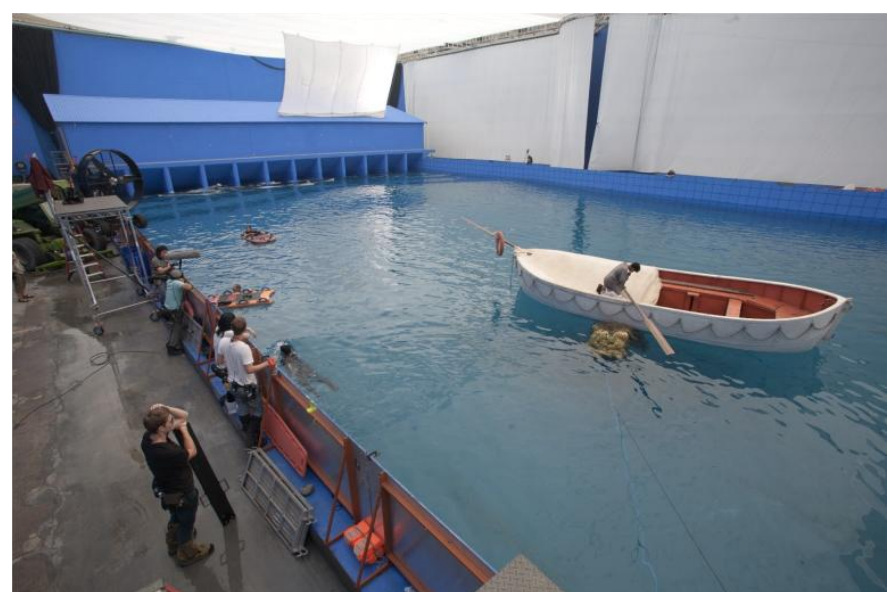

The sky too features prominently in the movie almost like another important character. For this the creative team had to literally sit on the beach of Florida to click pictures which could be actually used to create the desired effect. ""Naively," admits Westenhofer, "when we started the project I thought we'll just go grab a bunch of HDRI skies off the web. To my dismay there were barely any and those that did exist weren't of great quality. So someone's job had to be - go take our HDRI rig modified to shoot eight different directions with six exposure settings which combined into a 15K HDR skydome that we used as our backgrounds." (as qtd in fxguide, Failes)

The movie features two storm sequences in dark as well as in a broad daylight, which posed further challenge for the creators in terms of simulating it digitally. Creating waves with each accurate ripple to depict realistic effect of the same too seemed big a challenge for the creators. Semlyen in an analysis notes, "Waves in Pacific storms are 40 feet high and 80 feet long - they hit every ten to 12 seconds - and there's spray and white water caused by the wind."'The director's visualization of ocean as scary and dark gets rendered successfully by the visual effect of making ocean look more black instead of blue or white. The visual supervisor and his team achieved it by playing and manipulating with the screen and the effect was equally impressive. It's a bit different from reality, but it's the emotion of what Ang wanted. Semlyen further adds, "The Storm of God was even bigger and it's in full daylight so it's not about a black ocean. Instead, [we added] spray and mist to make it look very, very crazy. We took reality and amped it up."

Capturing reality on camera is easy since there is a natural course to the way things are happening around us but creating something from imagination or emulating something as powerful as nature or as dangerous as a beast and making it act to suit your fictional requirement is definitely challenging. Digital cinema has today made that possible for the movie makers catering to the minds seeking thrill and adventure on the silver screen.

The movie is a fine blend of reality with technology, real with unreal and actual with conceptual. It is listed as one of the finest visual treats ever offered to the audiences and one of the masterpieces of the digital cinema. This kind of a creation takes time and effort to reach to the level it is today but is a success story in itself of the way technology can be exploited for the entertainment of the viewers by bringing for their sight unbelievable representations of life in the most believable manner. However, as a digitized achievement, the movie may be par excellence but that also deters one from experiencing the pleasure of watching and relating with the plot while one gets lost in its technical enchantment.

\section{References}

Semlyen, Phil De. "Before And After: A Look At Life Of Pi's Visual Effects." Www.empireonline.com. Bauer Consumer Media Ltd, 20 Dec. 2012. Web. 26 Jan. 2016. <http://www.empireonline.com/movies/features/life-pi-vfx/> 
James, D. "How Much of the Tiger in 'Life of Pi' Was Real?". Parade. New York: Athlon Publishing.February 24, 2013

Horton, Robert. 'Life of Pi' transcends unreal special effects'. Herald Net.Washington: The Herald of Everett.November 21, 2012.

Failes, Ian. "Life of Pi: A Tiger's Tale." www.fxguide.com. Fxguide, 26 Nov. 2012. Web. 26 Jan. 2016. <https://www.fxguide.com/featured/life-of-pi/>.

"Ocean of Possibilities: The Making of Life of Pi." Interview by Trevor Hogg. Flickering Myth.com. Flickering Myth, 24 Feb. 2013. Web. 26 Jan. 2016. <http://www.flickeringmyth.com/2013/02/oceanof-possibilities-making-of-life.html>. 